This is a peer-reviewed, accepted author manuscript of the following conference paper: Kristoffersen, J. C., Bredmose, H., Georgakis, C. T., \& Tao, L. (2019). Preliminary experimental study on the influence of the local wind field on forces from breaking waves on a circular cylinder. In Ocean Engineering [95179] (Proceedings of the International Conference on Offshore Mechanics and Arctic Engineering - OMAE; Vol. 7B-2019). American Society of Mechanical Engineers (ASME). https://doi.org/10.1115/OMAE201995179

\title{
PRELIMINARY EXPERIMENTAL STUDY ON THE INFLUENCE OF THE LOCAL WIND FIELD ON FORCES FROM BREAKING WAVES ON A CIRCULAR CYLINDER
}

\author{
Julie Caroee Kristoffersen \\ Department of Engineering \\ University of Aarhus \\ Inge Lehmanns Gade 10, \\ 8000 Aarhus C, Denmark \\ Email: jck@eng.au.dk \\ Christos Thomas Georgakis \\ Department for Engineering \\ University of Aarhus \\ 8000 Aarhus C, Denmark
}

\author{
Henrik Bredmose \\ DTU Department of Wind Energy \\ Technical University of Denmark \\ Nils Koppels alle, \\ 2800 Kgs Lyngby, Denmark
}

\author{
Longbin Tao \\ University of Strathclyde \\ 16 Richmond street, \\ Glasgow G1 1XQ \\ United Kingdom
}

\begin{abstract}
The spatial localized influence of wind on wave induced load on a flexible cylinder has been assessed throughout a test series conducted in a wave-wind-current flume at Newcastle University. The tests are motivated from other experimental and numerical investigations showing air flow separation on the leeward side of steep waves that can lead to added wind energy transfer, which could suggest an increase in the impulsive wave loading. The waves are generated as focused waves, resulting in a plunging breaker, leading to an impulsive wave load. The test model was equipped with a load cell measuring the connection load. Due to the flexibility of the cylinder, the measured force response shows oscillations and dynamic amplification of the load. The maxima of the force responses are compared for the tests with and without wind. Another measure for comparison is the local and short-lived impulse, which is responsible for the amplification. This impulsive load is estimated from the load cell and acceleration measurements. For the tests in this study, the introduction of wind over the breaking waves does for some cases lead to a slight increase in the peak of the impulsive load and thereby the load response, although large scattering is present. Further investigations are needed to verify this effect. Some differences in the time series of the free surface elevation are observed when wind is present, but the maximum of the
\end{abstract}

surface elevation does not change notably, and the slope is only minimally changed, meaning that this should not give basis for the differences in the loads.

\section{KEYWORDS}

Offshore Structure, Wave-induced Load, Focused Wave, Breaking Wave, Wind influence, Airflow Separation

\section{INTRODUCTION}

Various researchers have conducted a large number of experiments on loads from breaking waves. Locally a very high impulsive pressure is generated, which must be taken into account in the design of components and joints on offshore structures. The concern in the overall design of offshore structures as monopiles and jacket structures, is on the amplification of structural response due to the impulsive nature of the force for waves of steepness at or close to breaking. In various researchers attempt to setup an analytical model for the impact itself, the approaches from Wagner [1] and from Von Karmen [2] are followed. Their models describe the impact by means of an added mass with a flat plate approximation with a width corresponding to the immersed part of the cylinder. The approaches deviate from each other because Wagner takes the pile up effect into account, meaning that the slamming factor becomes two times higher. With these approaches as reference, 
different analytical models are developed, which try to describe the increase of added mass as a function of time, and thereby describe the impact from the wave celerity and the temporal distribution of the impulse. This results in models with different

slamming factors and duration of the impact. With Von

Karmen's model as reference, Goda [3] formulates an impact with a slamming factor decreasing linearly from $\pi$ to 0 , during the full immersion of the cylinders diameter. In Wienke and Oumeraci [4], the model is developed from Wagners approach and results in a slamming coefficient decreasing stepwise in a polynomial form from $2 \pi$ to 0 during the immersion of nearly half the diameter. Their model is in good agreement with their experimental measurements on large scale waves. The different approaches to describe the complicated phenomena of a breaking wave impact, has resulted in a large number of load models with different slamming coefficients and temporal evolutions.

The amplification of the overall force, due to a breaking wave, is also reported with large variations. In Kjeldsen et al. [5], an amplification factor on the total force for two-dimensional plunging waves is found to be up to three times the forces from regular non-breaking waves. Moreover, the dynamic amplification will have variations depending on the duration of the impulse and the natural frequency of the test object. Wedel et al. [6] reports an amplification factor of the force response of 1.5. In Tychsen et al. [7] a dynamic amplification factor on 1.5 is inferred, and in addition, this factor is calculated ranging from 1.5-1.9, for natural frequencies relevant for offshore structures, when considering a single degree of freedom system.

To the knowledge of the author, no experimental investigation has been conducted to determine loads from breaking waves in the presence of wind. It should be noted that several experiments on the influence of the wind field on the wave field and vice versa, have been performed, and their findings are summarized here. Touboul et al. [8] examined the local effect from wind over a high and steep wave experimentally and numerically, by introducing the theory of Jeffrey's sheltering mechanism to the wave formation model. The waves were generated as focusing waves, and tests were conducted with and without wind. Introducing wind extends the duration of the time the waves are focused. Moreover the focal point is moved further downstream, which is explained in Giovanangeli [9] with a current introduced in the flume, when wind is blowing over the surface. If the same physics regarding wind over waves applies to wave groups on the open sea, the waves will stay focused for a longer duration. An extension of the duration of the focused wave could increase the risk that the wave hits a platform when being at its highest. In Kharif et. al. [10], an air flow separation (AFS) probe, consisting of X-hot wire and X-cold wire, confirms the AFS introduced on the leeward side of a high and steep wave, and the resulting enhancement of the energy transfer from wind to waves. Additionally it is observed that wave breaking often follows AFS, suggesting that the local wind effects will cause more waves to break. Reul et al. [11] performed tests particularly with wind over breaking waves. These tests also revealed AFS and in some cases vorticity on the leeward side of the breaking wave, depending on the type of breaker and slope. The separation of the flow over a plunging breaker occurred with higher intensity than over a spilling breaker, and increased the local wind stress related to energy transfer to the wave. For the numerical simulations it is discussed, that Jeffrey's sheltering mechanism might not capture all of the physics regarding the interaction between the wind field and breaking waves. They are mentioning in particular the drag form for the vortexes created on the lee side of steep waves and intermittent vertical mixing of horizontal vorticity in the airflow. Marino et al. [12] investigated the impulsive loads from breaking waves performing numerical simulations of waves affected by local wind stresses modelled with Jeffrey's sheltering mechanism. Despite the aforementioned experiments indicating an influence of the local wind stresses on the kinematics and dynamics of waves, the

simulations showed no significant influence on the loads. In this study a focused wave is generated and is breaking just in front of a circular cylinder equipped with a load cell to evaluate the loading. The low pass filtered signal of the load cell is compared to a calculated force. To calculate the force, the

NewWave theory are at first applied to describe surface elevation and wave kinematics up to second order. The kinematics are then used to calculate force by means of Morison equation with terms up to second order. The paper moreover contains an assessment of the forces from breaking waves and a discussion of the influence of wind on the impulsive force. Due to the model's flexibility and the short-lived impulse, the entire external force is not transferred throughout the structure and to the load cell. The external force on the structure is therefore estimated from both the measured connection force and accelerations.

\section{EXPERIMENTAL SETUP}

The test setup aims at reproducing conditions for offshore structures located in intermediate to deep water $(81 \mathrm{~m}$ full scale) exposed to extreme waves with a maximum wave height of $19.0 \mathrm{~m}$ (full scale). The wind velocity in the tests was $37.5 \mathrm{~m} / \mathrm{s}$ (full scale), which can represent a sea state with $\mathrm{Hs}$ around $12.0 \mathrm{~m}$. The tests were conducted at scale 1:90 in the wave-wind-current flume at Newcastle University, with two cylindrical model both having a diameter of $0.05(4.5 \mathrm{~m}$ full scale). The flume is $11.0 \mathrm{~m}$ long, $1.8 \mathrm{~m}$ wide, and has a water depth on $0.9 \mathrm{~m}$. It was equipped with three translational wave boards for wave generation, an air clearance of $1.0 \mathrm{~m}$ from the water surface to the cover for wind generation, and current inlet below the wave boards (see Fig. 1). Waves and wind were generated from one end of the flume, and a wave absorber was 
located in the opposite end, i.e. wind flow in the direction of the waves was applied. Two models - one in pvc and one in steel were installed in the tank. By having two models disturbance can be created in the wave field, i.e. radiation waves reflected from one model can interact with the incidents wave coming towards the other model. This effect is however assumed negligible due to the small diameter of the model compared to the wave height. The model in focus for this study was a $1.3 \mathrm{~m}$ tall cylindrical steel pipe representing a corresponding leg of a platform. The scaling were 1:90 using Froude scaling for dynamic similitude; hence, the diameter of the model was $50 \mathrm{~mm}$. The model was constrained at the bottom, $9.0 \mathrm{~m}$ downstream the wave paddles, and was equipped with sensors as seen on Fig. 1. The setup had a natural frequency of $4.1 \mathrm{~Hz}$, when the steel pipe was clamped and the water depth was $0.9 \mathrm{~m}$. Loads are measured with a 6DOF ATI mini 58 load cell [15], where the shear force and moment are evaluated. A Brüel \& Kjær piezoelectric accelerometer, type 4508B [16], was placed on top of the model. For surface elevation measurements, nine resistance wave gauges were placed along the length of the flume as seen in Fig. 2. All equipment were recording with a sample frequency of $2560 \mathrm{~Hz}$. Two wave configurations were applied to generate focusing waves of different crest heights. Both were breaking just in front of the cylinder at a predetermined focal point. Tests with two different crest heights are chosen to see the dependency of crest height and steepness on the effect of wind on the wave induced load. The characteristics of the spectrum for the two wave configurations are listed in Table 1 . The final program consisted of tests with the two configurations with and without wind. In Table 2, an overview of the conditions in the test is specified.

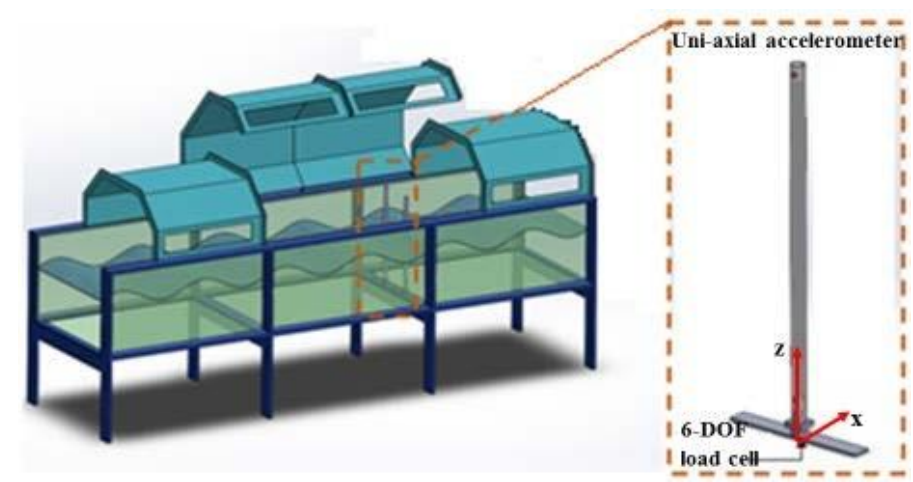

Figure 1: EXPERIMENTAL SETUP, STEEL MODEL WITH LOAD CELL IN BOTTONW AND ACCELEROMETER ON TOP.

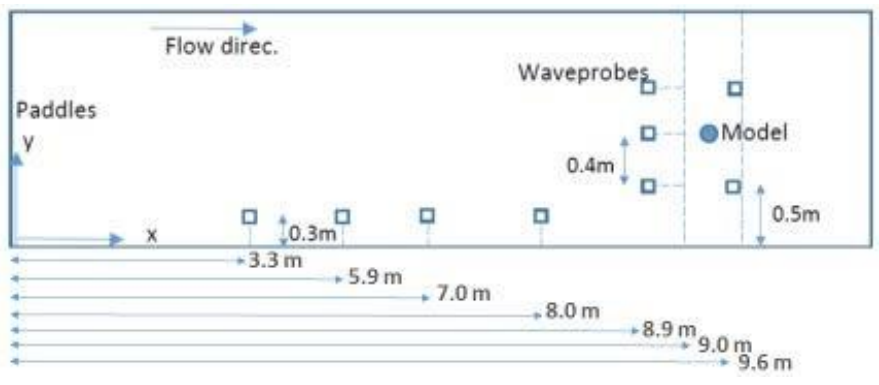

Figure 2: LOCATION OF WAVE PREOBES IN WAVE FLUME.

Table 1: WAVE PARAMETERS, CONFIGURATION I AND II, WHERE $x_{\text {foc }}$ IS THE FOCAL POINT OF THE WAVE TRAIN, $\eta_{\text {crest }} I S$ MAXIMUM CREST HEIGHT

\begin{tabular}{|l|l|c|c|c|c|}
\hline \multicolumn{2}{|l|}{$\begin{array}{l}\text { Wave } \\
\text { conf./ } \\
\text { parameters }\end{array}$} & \multicolumn{2}{|c|}{ Wave conf. I } & \multicolumn{2}{c|}{ Wave conf. II } \\
\cline { 2 - 6 } & Lab & $\begin{array}{c}\text { Full } \\
\text { scale }\end{array}$ & $\begin{array}{c}\text { Lab } \\
\text { scale }\end{array}$ & $\begin{array}{c}\text { Full } \\
\text { scale }\end{array}$ \\
\hline $\mathbf{\eta}_{\text {crest }}$ & {$[\mathrm{m}]$} & 0.128 & 11.5 & 0.16 & 14.5 \\
\hline $\mathbf{f}_{\mathbf{p}}$ & {$[\mathrm{Hz}]$} & 0.70 & 0.07 & 0.70 & 0.07 \\
\hline $\boldsymbol{\gamma}$ & {[]} & 3.3 & 3.3 & 3.3 & 3.3 \\
\hline $\mathbf{H}_{\text {max }}$ & {$[\mathrm{m}]$} & 0.17 & 15.3 & 0.21 & 19.0 \\
\hline $\mathbf{X}_{\text {foc }}$ & {$[\mathrm{m}]$} & 8.9 & & 8.9 & \\
\hline
\end{tabular}

Table 1: TEST MATRIX WITH TEST CONDITIONS

\begin{tabular}{|l|c|c|}
\hline Condition / & \multicolumn{2}{|c|}{ Wind [m/s] } \\
\cline { 2 - 3 } Wave configuration & Lab scale & Full scale \\
\hline I & 0 & 0 \\
\hline II & 4.0 & 37.5 \\
\hline II & 0 & 0 \\
\hline
\end{tabular}

During the test with wind, the focal point of the wave group and thereby the breaking of the wave appeared further down the flume, meaning that the wave did not focus at the point specified by the wave generator. To enable comparison of the load for the different conditions, some preliminary tests with varying defined focal points were performed. The selected focal point for the repetitive tests were determined through a collective evaluation of loads, surface elevation and video recordings, which is elaborated in the discussion section. Finally ten repetitions for each condition listed in Table 2 were performed. 


\section{SECOND ORDER SURFACE ELEVATION AND WAVE LOAD}

A focusing wave train can be described by NewWave theory as outlined by Tromans et al. [13], by using the spectral components of the Jonswap spectrum and assigning them aligned phases. The first order surface elevation is defined as

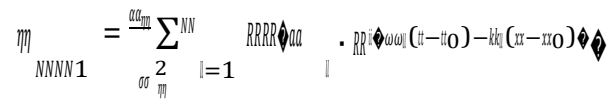

Where $a a_{m}$ is the crest height, $\sigma o_{m}^{2}=\int_{0}^{\infty} \delta S(\omega \omega) \mathrm{d} \omega \omega$,

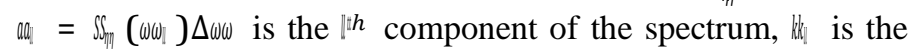
corresponding wavenumber, $\omega\left(\omega_{1}\right.$ the radian frequency, $x_{0}$ the focal point, and $t_{0}$ the focusing time. $N$ is the number of discretized frequency components of the spectrum. It should be mentioned that the components of the spectrum used in the test were generated as $\left\{f\left(f^{\prime}\right)\right.$, where $s s(\omega / \omega)$ was a Jonswap spectrum. This implies that the focused wave is equivalent to a NewWave, however for a differently shaped spectrum.

The second order surface elevation can be calculated with the second order solution provided by Sharma and Dean, 1981 [14]

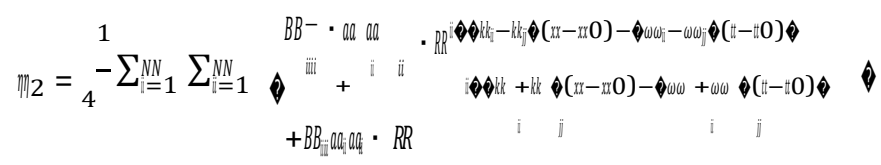

Where $B B_{\text {iii }}^{-}$and $B B_{\text {iii }}^{+}$is respectively the negative and positive interaction kernel and $a a_{i i}$ and $a a_{i i}$ is the spectral components of the first order spectrum. The velocity potential for NewWave theory of a focusing wave can as well be described with a first and second order solution. The first order solution is given as

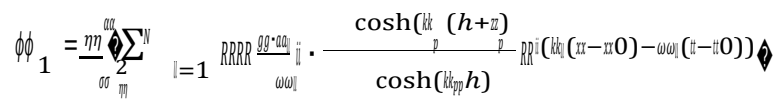

The second order solution of the velocity potential can be found in Sharma and Dean, 1981 [14].

The quasi-static wave loads, F can be estimated by computation of the kinematics of the wave up to $2^{\text {nd }}$ order and usage of Morison's equation extended with Rainey's [15] additional terms for diffraction and the point load at the free surface, so that $F F=\rho \rho R R c c \int_{d d}^{O}(u(1) \phi u(1) \emptyset) d d d d+$

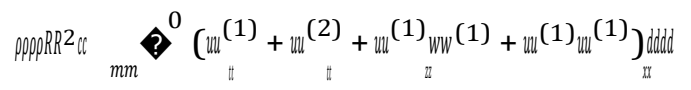

$$
\begin{aligned}
& \bar{h}
\end{aligned}
$$

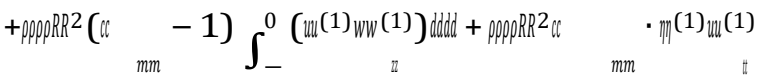

$$
\begin{aligned}
& \text { h }
\end{aligned}
$$

Where $R R$ is the radius of the cylinder, $u u$ and $w w$ are the velocities in the $x$ - and $z$-directions respectively, $u_{m m}$ and $u_{d d}$ are the inertia and drag coefficients, which are determined to 2.0 and 1.2 respective. Subscripts imply derivation and superscripts the order of the term. The first and second term are the drag and inertial term from Morison's equation, respectively. The third term is the term Rainey gave for diffraction in the vertical direction for a non-slender body. The last term is a point load obtained by integration of the first order inertial load from 0 up to $m$.

\section{DETERMINATION OF EXTERNAL FORCE}

The external force on the structure is estimated from

both the measured force and accelerations measured on top of the cylinder. The accelerations are used to correct for the oscillations from the dynamics of the model measured as part of the shear force with the load cell. The external force can be found by use of the equation of motion of a beam

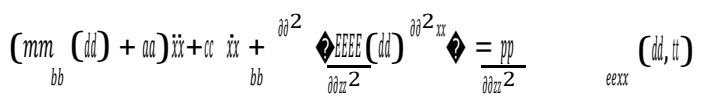

where $m m_{b b}(d)$ is the structural mass of the cylinder in each cross section, $a a$ is the hydrodynamic added mass for horizontal movements, EE and $\mathbb{E}(d)$ are the E-modulus for steel $(210 \mathrm{GPa}$ applied) and moment of inertia in each cross section of the cylinder, is the damping coefficient, $\ddot{x} \ddot{x}, \dot{x}, x, x$ are the acceleration, velocity and displacement of the cylinder respectively. See definition of $\mathrm{x}$ - and $\mathrm{z}$-direction in figure 1 . The damping term is assumed negligible as the structural and hydrodynamic damping was below $5 \%$ of critical combined. Integrating Eq. 5 over the length of the beam and setting $x(d d, t)=\phi \phi(d n) q(t)$, where $\phi \phi(d n)$ is the mode shapes and $q(t)$ the modal coordinates, so that

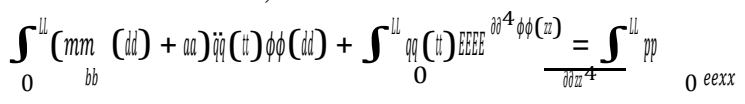

The second term in Eq. 6 is set equivalent to the shear force measured with the load cell $\mathbb{F}_{\text {mmenmm }}$. The model is assumed to deflect according to the first mode shape only, which inspections of the response spectrum reveals as a reasonable assumption.

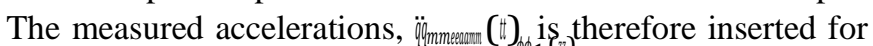

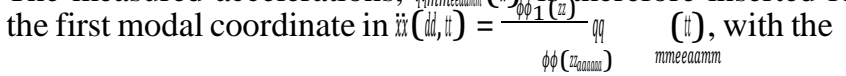
accelerometer's location taken into account, so that

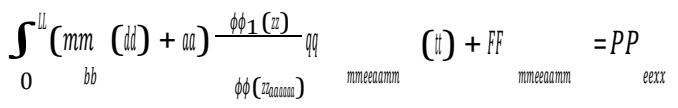

Due to some flexibility in the support of the model, $\phi \phi_{1}(d d)$ is found modelling the cylinder as a beam with a rotational spring as the support, and fitting the system to the $1^{\text {st }}$ and $2^{\text {nd }}$ natural frequency of the physical model. 


\section{DISCUSSION - EXPERIMENTAL RESULTS}

Prior to the final tests, the input of the focal point to the wave generator was calibrated for the test cases with and without wind. The approach was to compare the measured force with the measured distance from the model to the point at which the wave broke. The distance resulting in the highest load was chosen for the test repetitions. In Fig. 3 it can be seen that the shear force increases with decreasing distance from breaking point to the model until a maximum is reach around 0.10 and $0.12 \mathrm{~m}$ from the model for the test case with and without wind respectively. This means that the largest loads were achieved when the wave broke just in front of the structure, having a vertical breaker tongue as seen in Fig. 4. As an outcome of these results, the focal point were defined such that the waves broke 0.10 and $0.12 \mathrm{~m}$ before the model in test with and without wind respectively, and ten repetitions were performed for all test cases.

\section{Repetition test}

As reference in the discussion, the raw data for one of the tests with a focusing breaking wave is presented in Fig. 5. A steep wave event is observed in the time series of the surface elevation, at the time the wave is breaking. This is accompanied by a sudden rise in the acceleration level and the model vibrates in it's $1^{\text {st }}$ and $2^{\text {nd }}$ natural frequencies.

The measured surface elevation of a case with no wind is compared to the NewWave computation of a focused wave from a Jonswap spectrum. The input spectrum is found by using the signal from the wave gauge closest to the paddle. The spectrum is cut off at $1.0 \mathrm{~Hz}$ to obtain the first order surface elevation (see Fig. 5). By means of these first order components, the second order surface elevation is computed. This is done to obtain the kinematics of the wave and compute the quasi-static hydrodynamic force, which is compared to the low pass filtered force for the particular wave configuration.

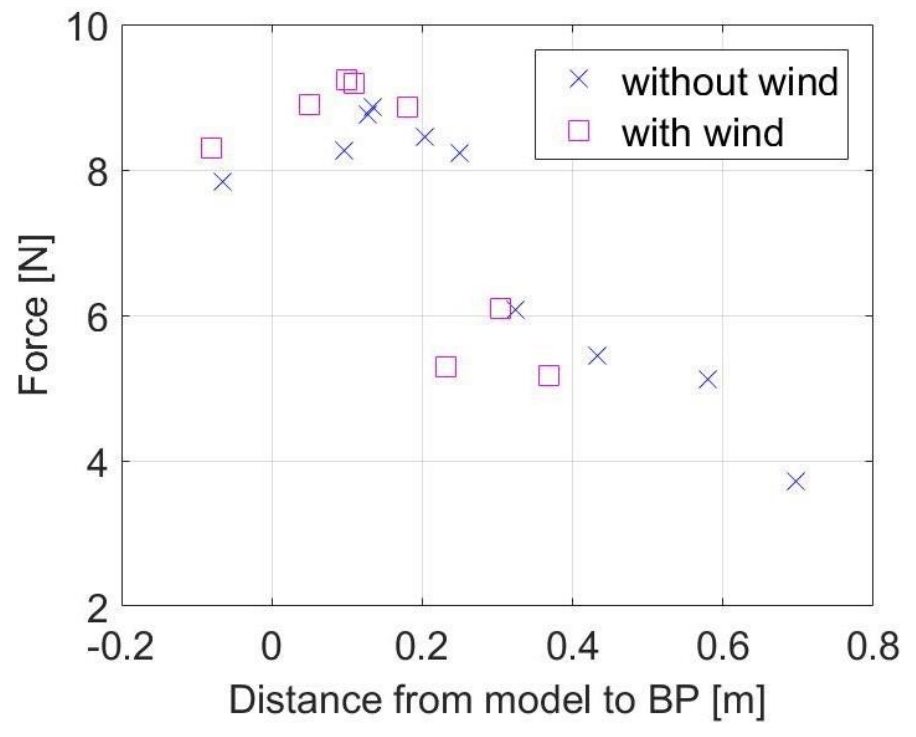

Figure 2: MEASURED FORCE AS FUNCTION OF DISTANCE FROM MODEL TO BREAKING POINT (BP).

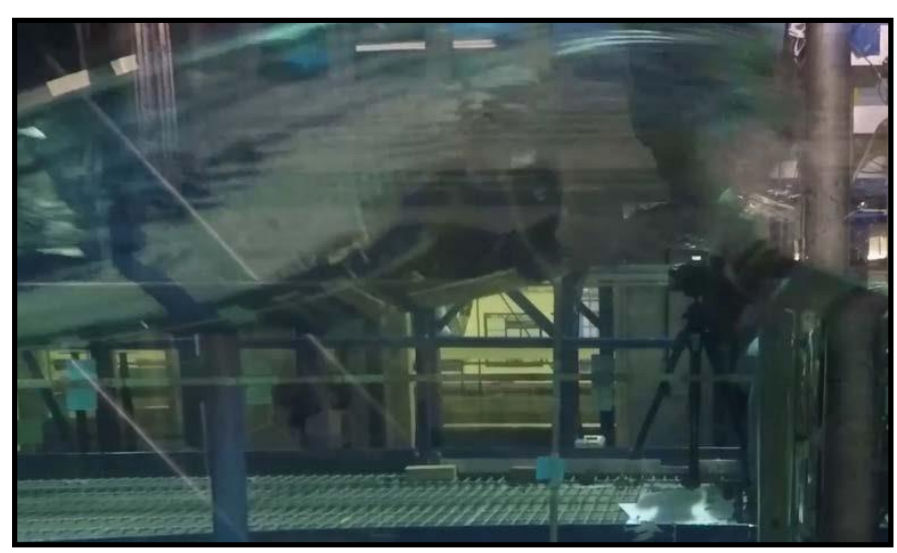

Figure 3: PICTURE OF BREAKING WAVE, SIDE VIEW FOR A TEST CASE WITHOUT WIND. 

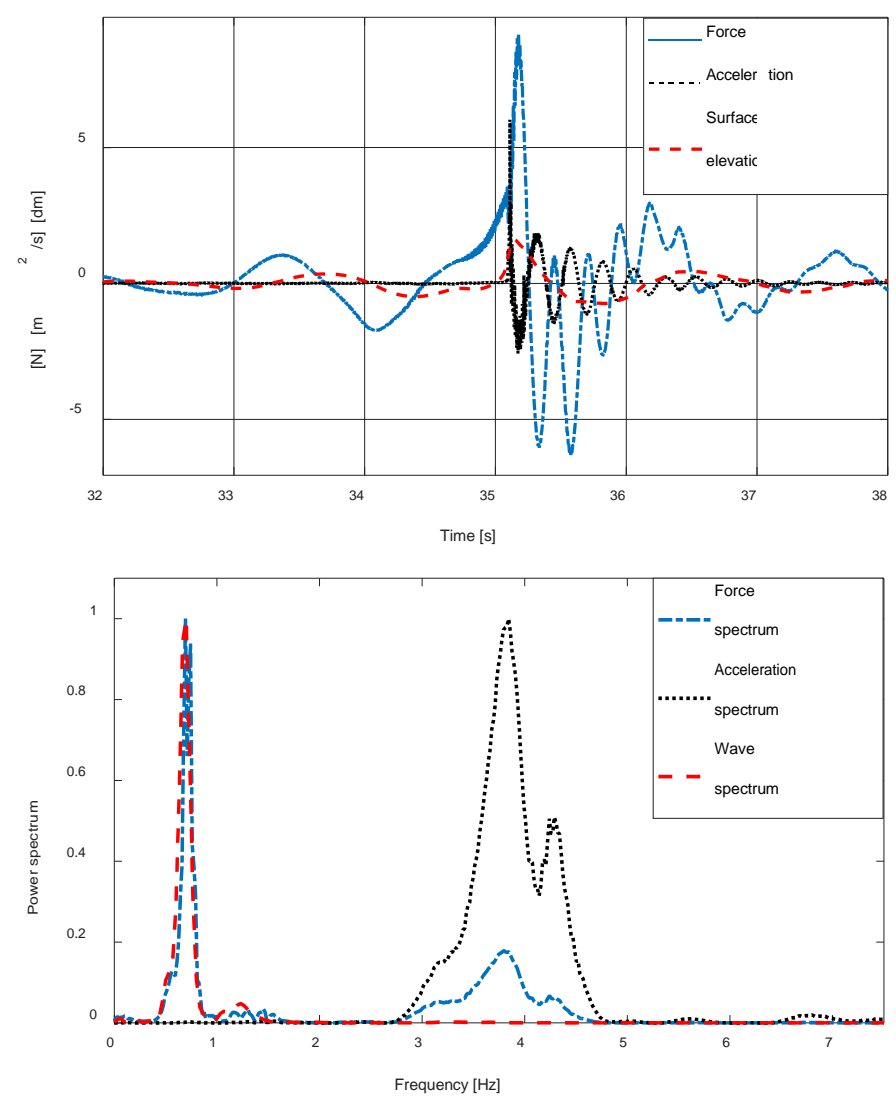

Figure 4: RAW MEASUREMENTS OF FORCE, ACCLERATION AND SURFACE ELEVATION FOR WAVE CONFIGURATION II IN TIME DOMAIN (TOP) AND FREQUENCY DOMAIN (BOTTOM).

Inspecting Fig. 6, top, the focused NewWave fits the measured surface elevation accurately except for the steepness of the wave around the breaking wave event. For Fig. 6, bottom, the low pass filtered force without the vibrations in the natural frequency is also modelled accurately with a $2^{\text {nd }}$ order Morison computation with NewWave kinematics, both the maximum and minimum values fits the measurements. It should also be mentioned that the repeatability in the tests is high for both the surface elevation and the low pass filtered portion of the force. The total measured force shown in Fig. 5 is nevertheless up to 1.7 times larger than both the computed and low pass filtered force because of dynamic amplification, which is not taken into account in the force computation. The dynamic amplification is between 1.6-1.8 for all tests.
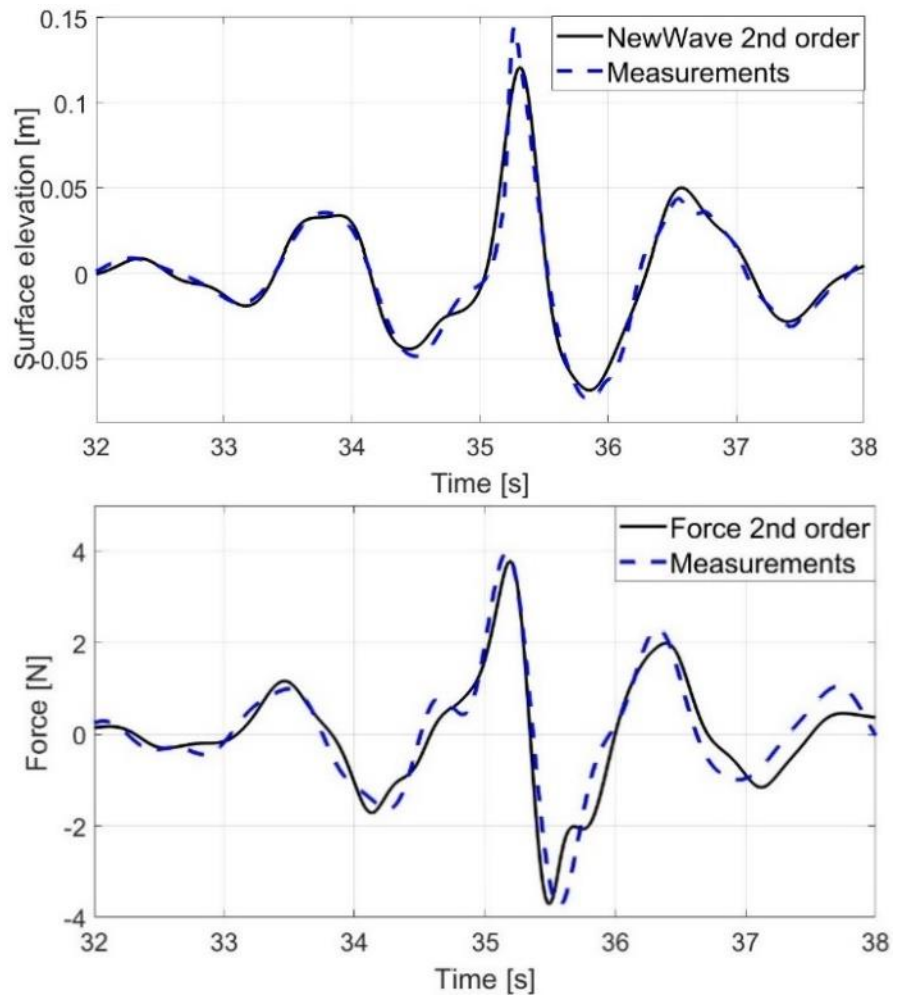

Figure 5: NEWWAVE SURFACE ELEVATION AND FORCE COMPUTATION VS MEASURED SURFACE ELEVATION AND LOWPASS FILTERED FORCE

\section{Comparison of tests with and without wind}

To ensure a proper basis for comparison of the forces for tests with and without wind, the similarity of the surface elevations is checked. Some differences are observed in the surface elevation for the two test cases seen in Fig. 7. The main difference is the additional small crest in the trough before the breaking event, which is more pronounced for the test case with wind. The maximum surface elevations and the slope of the breaking wave is nevertheless nearly the same for both cases. Therefore, this should not create a basis for any variations in the force. In Fig. 8 the force measurements from wave configuration II with and without wind is shown. A slight increase in the maximum force is observed for wave configuration II, when wind is introduced. In Table 3 and Fig. 9, the mean and standard deviation of the maximum total force for all conditions are shown. The mean value is $6.5 \%$ higher when wind is introduced over the waves for configuration II. The force for wave configuration I is on average decreased, when wind is introduced. There is however, a lot of scattering, particularly in the test with wind, i.e. both higher and lower force are measured for wave configuration I with wind compared to the case with no wind.

The dependency of the surface elevation on the maximum force in each test is plotted for wave configuration II, 
with and without wind, in Fig. 10. No clear trend is detected, and the highest forces occurs for some of the lowest surface elevations. Therefore, differences in the surface elevation can be ruled out as the main reason for the variations in the force response for test cases with wind. The dependency of the distance from the model to the breaking point on the force is also explored. The plot in Fig. 11 shows that the breaking point for tests with wind is $2-4 \mathrm{~cm}$ closer to the model. Despite this, there is no clear relation within the test case between the breaking point and the force. It is therefore still unclear which factors are responsible for the increase in wave-induced load, when wind is introduced. It could be explained with the randomness inherited in the maxima of the forces or it could be due to air flow separation and increased vorticity on the leeward side of the wave as detected in Reul, 2007 [11] and Kharif, 2008 [10].

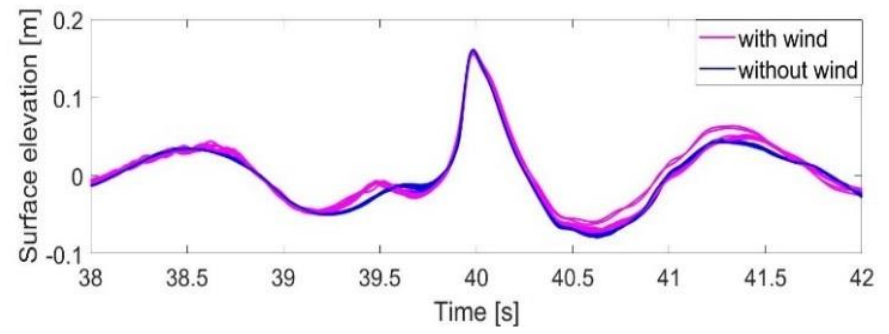

Figure 6: COMPARISON OF MEASURED SURFACE ELEVATION IN TESTS WITH AND WITHOUT WIND FOR WAVE CONFIGURATION II FOR 10 REPETITIONS.

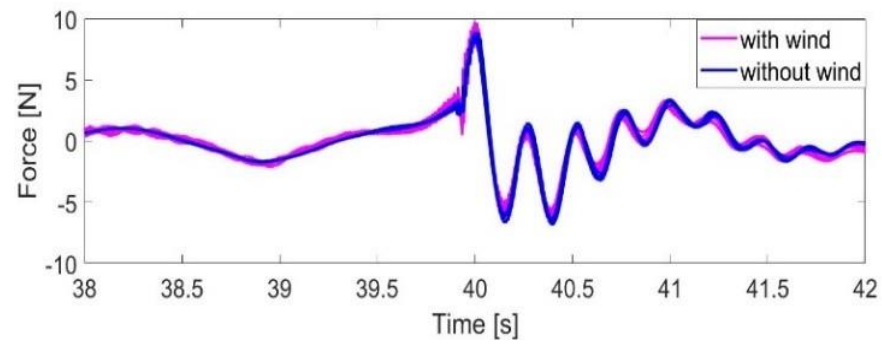

Figure 7: COMPARISON OF MEASURED FORCE IN TEST WITH AND WITHOUT WIND FOR WAVE CONFIGURATION II FOR 10 REPETITIONS.

Table 2: MEAN, $\mu$ AND STANDARD DEVIATION, $\sigma$ OF TOTAL MEASURED LOAD WITH AND WITHOUT WIND FOR WAVE CONFIGURATION I AND II

\begin{tabular}{|l|c|c|c|c|}
\hline $\begin{array}{c}\text { Maximum } \\
\text { of shear } \\
\text { force }\end{array}$ & $\begin{array}{c}\text { Conf. I } \\
\text { without } \\
\text { wind }\end{array}$ & $\begin{array}{c}\text { Conf. I } \\
\text { with } \\
\text { wind }\end{array}$ & $\begin{array}{c}\text { Conf. II } \\
\text { without } \\
\text { wind }\end{array}$ & $\begin{array}{c}\text { Conf. II } \\
\text { with } \\
\text { wind }\end{array}$ \\
\hline $\boldsymbol{\mu}[\mathbf{N}]$ & 5.34 & 5.14 & 8.80 & 9.37 \\
\hline $\boldsymbol{\sigma}[\mathbf{N}]$ & 0.12 & 0.54 & 0.26 & 0.35 \\
\hline
\end{tabular}

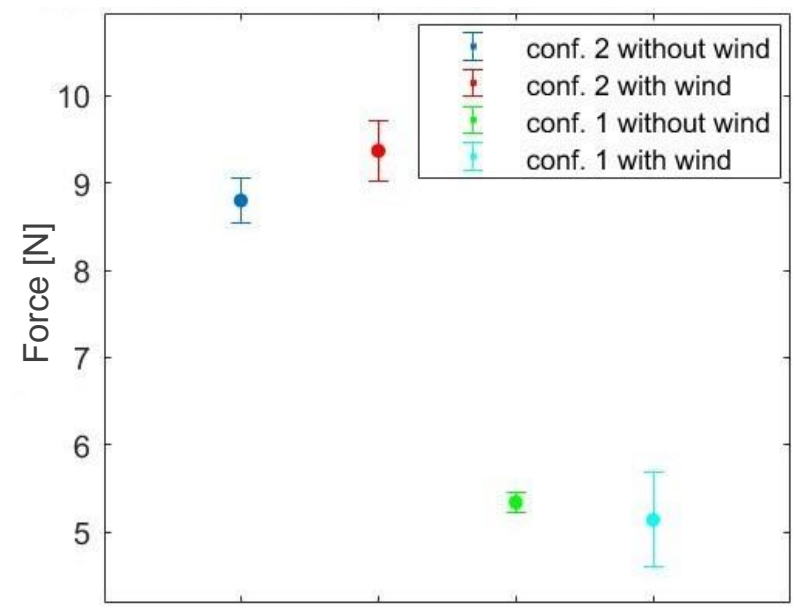

Figure 8: MEAN AND STANDARD DEVIATION OF MAXIMUM OF TOTAL LOAD WITH AND WITHOUT WIND FOR 10 REPETITIONS TEST IN WAVE CONF. I AND II

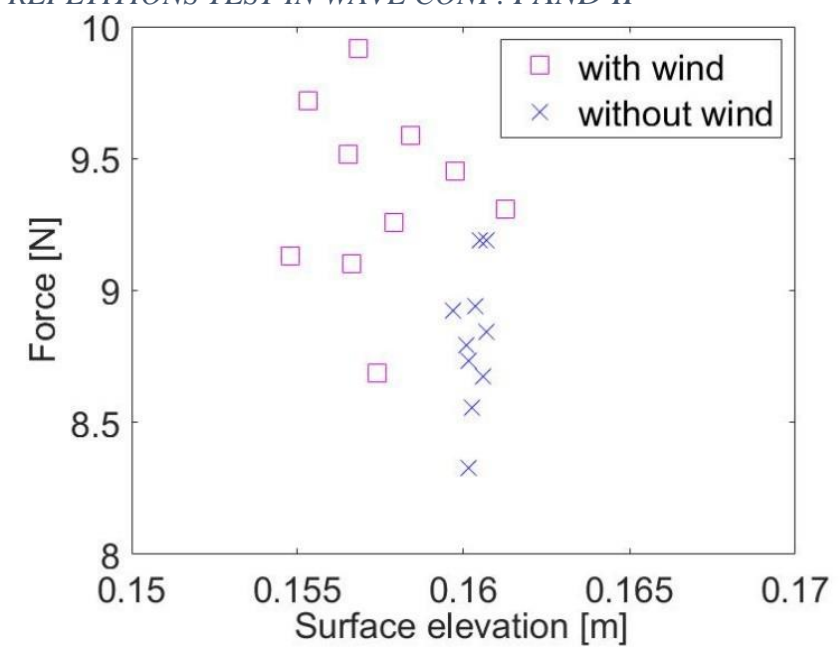

Figure 9: MAXIMUM OF FORCE AS FUNCTION OF MAX SURFACE ELEVATION FOR WAVE CONFIGURATION II.

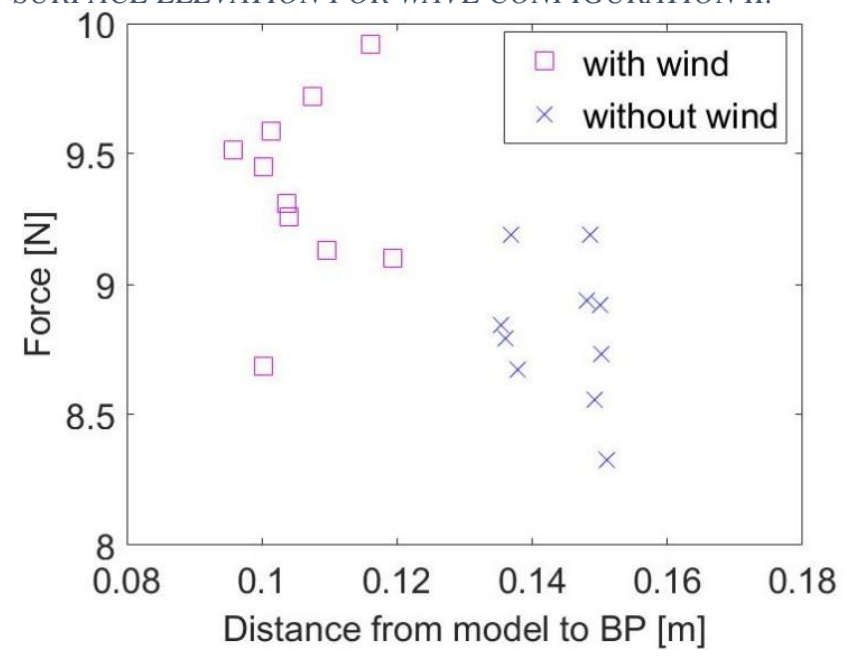

Figure 10: MAXIMUM OF FORCE AS A FUNCTION OF DISTANCE FROM MODEL TO BREAKIN POINT (BP) FOR WAVE CONFIGURAION II. 
A time series of the external force estimated from acceleration and force measurements is shown in Fig. 12. It can be seen that when the inertial force is added to the unfiltered load measurement from the load cell, the result fits the low pass filtered (quasi-static) load, expect from the additional impulsive load on top of the force crest, where breaking occurs. In this way, the external force generated by the breaking wave is achieved, even though it is not captured in the load cell measurement due to the short time duration of the impulse. Thereby we obtain a general measure for the external force for breaking waves. Elements, joint etc. that are in risk of being hit by a breaking wave should be designed for this local force. The external load is therefore compared for the different test cases for wave configuration I and II. The mean value and standard deviation of the maximum estimated impulsive force for all test is listed in Table 4. For wave configuration II, the impulsive force is on average increased by more than $25 \%$, when wind is included. The tendency for wave configuration $\mathrm{I}$ is that the maximum impulsive force is actually decreasing when wind is introduced above the waves. The increase in the force for wave configuration II when wind is included could be explained with an increased energy transfer from wind to the waves due to air flow separation. This phenomena is only present at high and steep waves and might therefore not develop behind the smaller waves in wave configuration I. Due to the low number of repetitions of the tests, it is not possibly to say if the increase in force when wind is included, is caused by increased wind transfer from local wind flow phenomena. Tests with a higher number of repetitions should be conducted, and in addition to that, the wind field should be measured thoroughly.

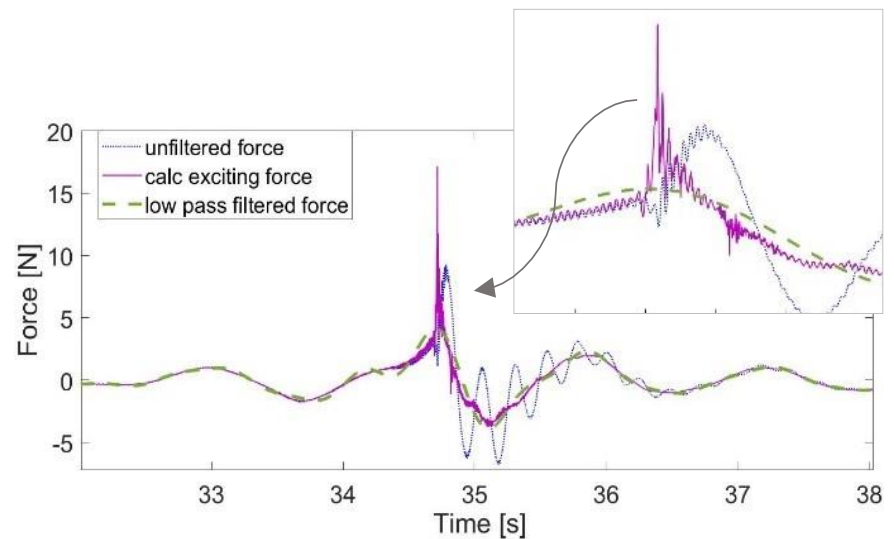

Figure 11: EXTERNAL FORCE FROM BREAKING WAVE (CONF. II) ON CYLINDER.

Table 3: MEAN, $\mu$ AND STANDARD DEVIATION, $\sigma$ OF EXCITING FORCE IN TEST WITH AND WITHOUT WIND OF CONF. I AND II.

\begin{tabular}{|l|l|l|l|l|}
\hline $\begin{array}{c}\text { Maximum } \\
\text { impulsive } \\
\text { load }\end{array}$ & $\begin{array}{l}\text { conf. 1 } \\
\text { without }\end{array}$ & $\begin{array}{l}\text { conf. 1 } \\
\text { with }\end{array}$ & $\begin{array}{l}\text { conf. 2 } \\
\text { without }\end{array}$ & $\begin{array}{l}\text { conf. 2 } \\
\text { with }\end{array}$ \\
wind & wind & wind \\
\hline $\boldsymbol{\mu}[\mathbf{N}]$ & 9.90 & 7.44 & 15.6 & 22.4 \\
\hline $\boldsymbol{\sigma}[\mathbf{N}]$ & 2.54 & 1.50 & 2.12 & 7.41 \\
\hline
\end{tabular}

As the existence of an air flow separation is depending on the steepness of the waves, this parameter is studied. The critical local slope providing the possibility for air flow separation over the waves, is estimated to be 0.35 in experimental investigations by Kharif et. al., 2008 [10]. To examine whether the increase of the wave forces in the wind tests can be attributed this phenomena, the local slope of the surface elevation is calculated from wave gauge measurement through the dispersion relation, i.e. the measurements is differentiated spatially. This is validated against slopes estimated from video recordings. The duration that the local slope is above 0.35 for different positions in the flume is shown in Fig. 13 together with the maximum of the slope. The wave configuration II evolves in a wave train with slopes higher than the critical of 0.35 for a longer duration than configuration I, meaning that the potential for an increase in wind transfer due to air flow separation is larger. The waves stay in general over the critical slope for a longer duration when wind is introduced. The maximum slope is for all configurations increasing at the focal point of $8.9 \mathrm{~m}$, and the wave is slightly steeper at this point for tests with wind than without wind for configuration II. For wave configuration II with wind, there is an increase in the duration, where the wave slope is over the critical slope and the maximum slope increases. This shows that the required conditions for an increase in wind energy transfer due to air flow seperation is mainly present for configuration II. However, more measurements of the wind field would need to be conducted for this to be conclusive.

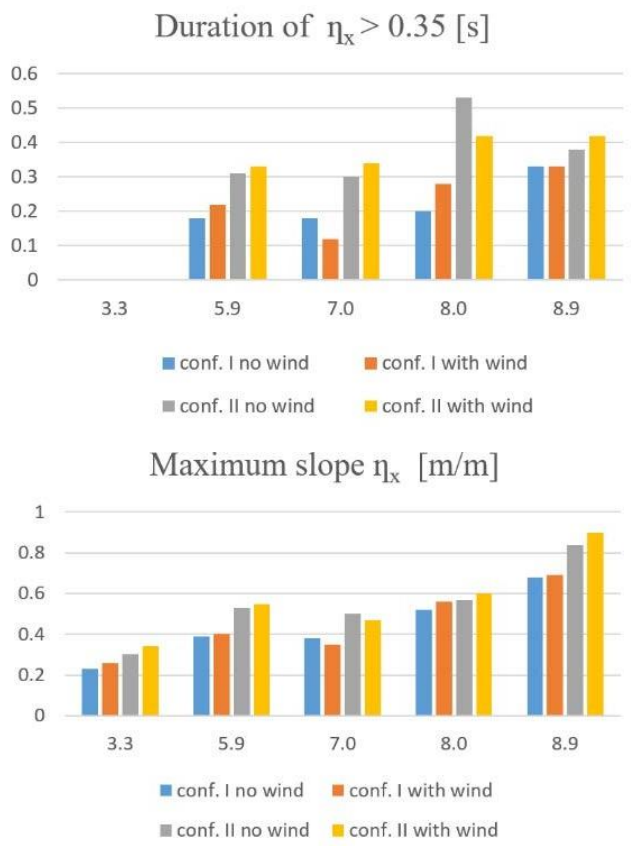

Figure 12: DURATION OF $\eta_{x}>0.35$ AND MAXIMUM SLOPE FOR 5 WAVE GAUGE MEASUREMENTS DOWN THE TANK. LOCATION 8.9 DOWN THE FLUME CORRESPONDS TO THE FOCAL POINT. 


\section{CONCLUSION}

The impulsive force from the breaking waves is resulting in a force response with clear harmonic oscillations corresponding to the $1^{\text {st }}$ and $2^{\text {nd }}$ mode of the model, providing a dynamic amplification of around 1.7. The maximum of the total force response is compared for test cases with and without wind and with different amplitude of the waves. For wave configuration I, with low wave amplitudes, there is a decrease in force response, when wind is introduced. For wave configuration II having the largest wave amplitude, the maximum of the force response is increased by $6.5 \%$ when wind is introduced. The short-lived impulse of the external force from a breaking wave is examined with both measurements from a load cell and an accelerometer. The maximum force value of this impulse is increased by $25 \%$ for wave configuration II when wind is introduced. This increase in the peak of the force response and in the peak of the external force impulse could be explained with an increase in wind energy transfer from airflow separation on the leeward side of a high and steep wave. Such phenomena in the wind field can give increased wave kinematic, and thereby increased load. The local wind field could also initiate breaking of the waves and thereby alter the breaking probability. Future work will elaborate on this matter with both numerical and further experimental studies.

\section{ACKNOWLEDGEMENTS}

The authors acknowledge the funding received from Centre of Oil and Gas - DTU/Danish Hydrocarbon and Technology Centre (DHRTC). The help from the technicians at the Hydrodynamics Laboratory at Newcastle University is appreciated.

\section{REFERENCES}

[1] Wagner, Herbert. "Über Stoß-und Gleitvorgänge an der Oberfläche von Flüssigkeiten." ZAMM-Journal of Applied Mathematics and Mechanics/Zeitschrift für Angewandte Mathematik und Mechanik 12.4 (1932):193-215

[2] Von Karman, Th. "The impact on seaplane floats during landing." (1929).

[3] Goda, Y., S. Haranaka, and M. Kitahata. "Study of impulsive breaking wave forces on piles." Report Port and Harbour Technical Research Institute 6.5 (1966): 1-30.

[4] Wienke, J., and H. Oumeraci. "Breaking wave impact force on a vertical and inclined slender pile - theoretical and largescale model investigations." Coastal Engineering 52.5 (2005): 435-462

[5] Kjeldsen, Søren Peter, Alf Tørum, and Robert G. Dean. "Wave forces on vertical piles caused by 2-and 3-dimensional breaking waves." Coastal Engineering 1986. 1987. 1929-1942.
[6] Nielsen, Anders Wedel, et al. "Wave loads on a monopile in 3D waves." International Conference on Ocean, Offshore and Arctic Engineering. 2012.

[7] Tychsen, Jesper, et al. "Summary of the impact on structural reliability of the findings of the Tyra Field extreme wave study 2013-15". The $3^{\text {rd }}$ Offshore Structural Reliability Conference. 2016

[8] Touboul, Julien, et al. "Freak waves under the action of wind: experiments and simulations". European Journal of MechanicsB/Fluids 25.5 (2006): 662-676.

[9] Giovanangeli, Jean-Paul, Christian Kharif, and Efim Pelinovski. "Experimental study of the wind effect on focusing of transient wave groups." arXiv preprint physics/ 0607010 (2006).

[10] Kharif, Christian, et al. "Influence of wind on extreme wave events: experimental and numerical approaches." Journal of Fluid Mechanics 594 (2008): 209-247.

[11] Reul, Nicolas, Hubert Branger, and Jean-Paul Giovanangeli. "Air flow structure over short-gravity breaking water waves." Boundary-layer meteorology 126.3 (2008): 477 505

[12] Marino, Enzo, Claudio Borri, and Claudio Lugni. "Influence of wind-waves energy transfer on the impulsive hydrodynamic loads acting on offshore wind turbines." Journal of Wind Engineering and Industrial Aerodynamics 99.6 (2011): 767-775.

[13] Tromans, Peter S., Ali R. Anaturk, and Paul Hagemeijer. "A new model for the kinematics of large ocean waves-application as a design wave." The First International Offshore and Polar Engineering Conference. International Society of Offshore and Polar Engineers, 1991.

[14] Sharma, J. N., and R. G. Dean. "Second-order directional seas and associated wave forces." Society of Petroleum Engineers Journal 21.01 (1981): 129-140.

[15] Rainey, R. C. T. "A new equation for calculating wave loads on offshore structures." Journal of Fluid Mechanics 204 (1989): 295-324.

\section{Webpages:}

[16] http://www.ati-

ia.com/products/ft/ft_models.aspx?id=Mini58

[17] https://www.bksv.com/en/products/transducers/vibration/ Vibration-transducers/accelerometers/4508-B 